DOI: $\underline{\text { https://doi.org/10.24867/11BE13Zec }}$

\title{
OBJEKTIVNA PROCENA SUBJEKTIVNOG KVALITETA RADIOGRAFSKIH SNIMAKA
}

\section{OBJECTIVE ASSESSMENT OF SUBJECTIVE RADIOGRAPHIC IMAGE QUALITY}

\author{
Aleksandra Zec, Fakultet tehničkih nauka, Novi Sad
}

\section{Oblast - OBRADA SIGNALA}

Kratak sadržaj - Objektivna evaluacija faktora koji utiču na kvalitet radiografskih snimaka pruža mogućnost optimizacije algoritama obrade u pravcu dostizanja kvaliteta slike koji zahtevaju radiolozi. U ovom radu predložene su mere količine šuma, kontrasta $i$ oštrine, dizajnirane tako da se njihova procena što više poklapa sa subjektivnim ocenama koje su dali radiolozi.

Ključne reči: objektivna procena šuma, objektivna procena kontrasta, objektivna procena oštrine, obrada medicinske slike

\begin{abstract}
Objective evaluation of radiographic image quality factors provides an opportunity for optimisation of image processing algorithms in order to meet the quality criteria of radiologists. Objective measures of noise, contrast and sharpness are proposed in this paper. The aim of the metrics is correspond to the scores given by radiologists as closely as possible.
\end{abstract}

Keywords: objective assessment of noise, objective assessment of sharpness, objective assessment of contrast, medical imaging

\section{UVOD}

Za pouzdanu dijagnostiku u radiologiji od presudnog značaja je visok kvalitet radiografskih snimaka. Da bi bila osigurana vrhunska zdravstvena nega, snimci moraju biti pouzdana i verna reprezentacija regije tela koja se snima, a njihov kvalitet mora da bude na nivou koji omogućava radiolozima da ih adekvatno analiziraju i sa dovoljnom sigurnošću izvode neophodne zaključke.

Glavni faktori koji određuju kvalitet slike su kontrast, oštrina i količina šuma. Objektivna kvantifikacija ovih karakteristika i procena njihovog uticaja na kvalitet snimka omogućila bi dodatno unapređenje algoritama za obradu slike [1] i automatsku optimizaciju kvaliteta radiografskih snimaka [2]. Takva procena mogla bi da se dobije objektivnim merama napravljenim tako da oponašaju subjektivni utisak o određenoj karakteristici snimka koji imaju radiolozi.

U ovom radu su definisane $\mathrm{i}$ analizirane objektivne mere šuma, oštrine i kontrasta. Njihov rezultat je evaluiran na osnovu poklapanja sa subjektivnim ocenama dijagnostičkih radiologa koji su analizirali skup snimaka i dali svoj utisak o tri komponente kvaliteta.

\section{NAPOMENA:}

Ovaj rad proistekao je iz master rada čiji mentor je bila dr Tatjana Lončar-Turukalo, vanr. prof.
U narednom poglavlju opisani su faktori koji utiču na subjektivnu percepciju kvaliteta. U trećem poglavlju predstavljene su objektivne mere faktora koji utiču na kvalitet. U četvrtom poglavlju opisani su korišćeni podaci. Nakon toga, u petom poglavlju, predstavljeni su rezultati, a zatim sledi zaključak.

\section{FAKTORI KOJI UTIČU NA KVALITET SLIKE}

Kvalitetna vizuelizacija snimane anatomske strukture zavisi od prirodnih karakteristika izabranog modaliteta i određenih parametara snimanja koje je moguće kontrolisati. Optimalna procedura snimanja podrazumeva da je pacijent izložen najmanjoj mogućoj dozi radijacije, tokom najkraćeg vremena, a da je pri tome kvalitet snimka dovoljno očuvan.

$\mathrm{U}$ procesu radiografskog snimanja snop fotona koji se formira u rendgenskoj cevi prolazi kroz pacijenta i pada na digitalni detektor. Rendgenski zrak koji prolazi kroz telo različito slabi pri prolasku kroz različita tkiva. Kontrast, jedna od osnovnih karakteristika slike, nastaje upravo zbog ove varijacije u slabljenju.

Da bi anatomska struktura bila vidljiva na snimku mora postojati dovoljno kontrasta u odnosu na okolno tkivo, što se ogleda kao razlika $u$ određenim fizičkim karakteristikama između te strukture i njene okoline. Glavni faktor jeste gustina i tip tkiva, a uticaj ima i debljina strukture koja se posmatra [3].

Poželjno je da su varijacije u intenzitetu slike prisutne samo na mestima gde postoje promene u gustini regije koja se snima. U potpunom odsustvu šuma, intenzitet snimka bio bi uniforman $\mathrm{u}$ okviru jedne strukture $\mathrm{i}$ menjao bi se na mestima prelaza iz jedne regije u drugu. Međutim, svi realni snimci sadrže određenu količinu vidljivog šuma, koji uzrokuje varijacije u intenzitetu čak i na mestima gde nema fizičkih promena u tkivu. Ove varijacije su obično nasumične i imaju efekat prošaranog, zrnastog sloja koji je dodat na sliku [3]. Veće prisustvo šuma spušta prag vidljivosti, što za posledicu ima maskiranje objekata koji su sitniji i slabijeg kontrasta.Efekat šuma je još nepovoljniji u slučaju kada je kontrast relativno nizak [3].

Veoma bitna karakteristika rendgenskog sistema je rezolucija, tj. red veličine bliskih anatomskih struktura koje je i dalje moguće razlikovati na snimku. Rezolucija prvenstveno zavisi od veličine piksela na detektoru, ali i od toga da svaki sistem za akviziciju snimaka unosi određeno zamućenje koje je posledica samog procesa snimanja, fizičkih ograničenja aprature za snimanje i mogućeg pomeranja pacijenta $[4,5]$. Ovo neizbežna 
pojava smanjuje vidljivost na visokim frekvencijama što kao efekat ima smanjenje oštrine snimka. Slika koja je bogata detaljima i koja sadrži jasne ivice je oštra, a zamućenje dovodi do gubitka oštrine, što najviše utiče na vidljivost ivica i granica struktura unutar slike [3].

Na Slici 1 (a) prikazan je snimak boljeg kvaliteta, a na (b) snimak lošijeg kvaliteta.

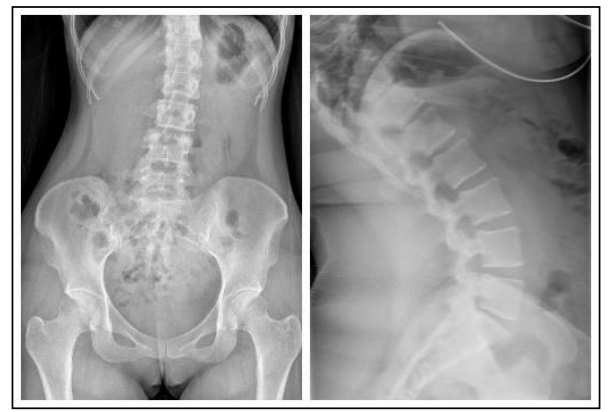

(a)

(b)

Slika 1. (a) Snimak abdomena boljeg kvaliteta, (b) snimak lumbalne kičme lošijeg kvaliteta

U opštem slučaju, variranje osetljivosti ljudskog vizuelnog sistema dešava se iz tri razloga [6], a to su nivo osvetljaja (na nižim osvetljajima moguće detektovati manje promene $\mathrm{u}$ intenzitetu, a sa porastom osvetljaja raste i minimalna razlika u intenzitetu koja može da se detektuje [7]), prostorna frekvencija (osetljivost na kontrast opada na krajevima frekvencijskog opsega [6]) i sadržaj signala (ako u opsegu postoji komponenta signala, to će podići prag detekcije druge komponente u tom opsegu [6]). Ova ograničenja se inkorporiraju kroz pragove maskiranja koji određuju nivo distorzije kojem slika može da bude izložena pre nego što promena postane vidljiva posmatraču.

\section{OBJEKTIVNE MERE KVALITETA}

Definisane su objektivne mere kontrasta, količine šuma i oštrine, u cilju da se dobije algoritam čija se procena što bolje poklapa sa rezultatima subjektivnog ispitivanja. Sve mere rade bez reference budući da su u pitanju snimci ljudskog tela, za koje ne postoji univerzalni model.

\section{1. Šum}

Za objektivnu procenu šuma korišćene su dve mere koje se zasnivaju na analizi strukturiranosti slike. Za detekciju značajnih struktura u snimku korišćena je lokalna koherencija ( $L C)$ ). $L C$ je karakteristika slike kojom se opisuje relativna orijentacija vektora gradijenta oko datog piksela. Može imati vrednosti iz opsega [-1,1]. Veće vrednosti ukazuju na veću lokalnu snagu gradijenta, što znači da se pravci vektora gradijenata više poklapaju u datom lokalnom regionu, što je slučaj kada postoje izražene strukture.

Gradijent slike $G$ predstavlja promenu intenziteta slike u nekom pravcu. $G_{x}$ su promene u horizontalnom, a $G_{y} \mathrm{u}$ vertikalnom pravcu, a snaga gradijenta se računa po sledećoj formuli:

$$
G=\sqrt{G_{x}^{2}+G_{y}^{2}}
$$

Izražene anatomske strukture u slici su više koherentne od šuma, a u krajnjem slučaju će maskirati šum koji je prisutan, pa se posmatraju kao čist korisni signal. Petpostavka je da u ostatku slike dominira šum, a njegova količina negativno utiče na visinu ocene koju daje mera (kao i na subjektivni utisak o kvalitetu).

Mera LC $_{1}$ koristi parametar optimizacije $T_{L C}$ kojim se definiše mera strukturiranosti regija koje ulaze u analizu kao koristan signal, a ostali delovi se obeleževaju kao nestrukturirani tj. šumoviti. Uveden je i parametar $T_{v d e t}$, koji definiše prag intenziteta iznad koga se smatra da je gradijent vidljiv

Pozicije na slici na kojima dominira strukturirani korisni signal su one na kojima su vidljive strukture većeg gradijenta $T_{v d e t}$, i nivo strukture veći od $T_{L C}$ :

$$
\begin{gathered}
M_{S}(n, m)=\left(G(n, m)>T_{v d e t}\right) \\
\&\left(L C(n, m)>T_{L C}\right)
\end{gathered}
$$

U ostalim oblastima dominira šum:

$$
M_{N}(n, m)=\neg M_{S}(n, m)
$$

Mera računa odnos ukupnog gradijenta strukturiranog signala $\left(M_{S} \cdot G\right)$ i ukupnog gradijenta šuma $\left(M_{N} \cdot G\right)$ :

$$
\mathrm{N}_{q}^{L C_{1}}=\frac{\sum_{\forall n, m} M_{S}(n, m) G(n, m)}{\sum_{\forall n, m} M_{N}(n, m) G(n, m)}
$$

Meka tkiva se po kriterijumu strukturiranosti nalaze negde između nasumično orijentisanog gradijenta šuma i visokog nivoa strukturiranosti koštanog tkiva. Zbog toga je i šum više izražen na ovim regionima. Tokom stručne analize slike, fokus je na regionima koji su od značaja za dijagnozu. Usled izražene strukturiranosti, u predelu kostiju i ostalih izraženih ivica može doći do maskiranja šuma, dok u regionu pluća, digestivnog trakta i ostalih mekih tkiva strukture nisu dovoljno izražene i subjektivni utisak o šumu je nepovoljniji.

Iz tog razloga je prilikom analize snimaka mekih tkiva neophodno $\mathrm{u}$ koristan signal uvrstiti $\mathrm{i}$ regije koje odgovaraju mekim strukturama $\mathrm{i}$ fokusirati procenu gradijenta na tim delovima. Mera $\mathrm{LC}_{2}$ u tu svrhu koristi dva praga za $L C$. Pomoću donjeg praga $L T_{L C}$ se eliminišu strukture koje pripadaju šumu, a gornji prag $U T_{L C}$ odbacuje najdominantnije strukture koje bi odvukle procenu od regiona od interesa za analizu:

$$
\begin{gathered}
M_{S}(n, m)=\left(G(n, m)>T_{d}\right) \& \\
\left(L C(n, m)>L T_{L C}\right) \&\left(L C(n, m)<U T_{L C}\right)
\end{gathered}
$$

Šum se procenjuje na mestima koja su ispod donjeg praga za $L C$ :

$$
M_{N}(n, m)=L C(n, m)<U T_{L C}
$$

Konačni rezultat mere je, kao i u prethodnom slučaju, odnos gradijenata na regionima sa značajnim strukturama i regionima na kojima dominira šum: 


$$
\mathrm{N}_{q}^{L C_{2}}=\frac{\sum_{\forall n, m} M_{S}(n, m) G(n, m)}{\sum_{\forall n, m} M_{N}(n, m) G(n, m)}
$$

\subsection{Kontrast}

Objektivna mera za procenu kontrasta zasniva se na proceni vidljivosti struktura. Da bi se procena zadržala na nešto krupnijim promenama, umesto samo na najfinijim detaljima, smanjuje se rezolucija ulaznog snimka. Dalja analiza se radi na određenom nivou Gausove piramide koji se bira parametrom optimizacije $L_{R}$. Gradijent se računa po (1), i definiše se vidljivi gradijent:

$$
G_{v i s}=G>T_{G_{v i s}}
$$

Lokalni kontrast $w q$ procenjuje se po prozorma veličine $5 \times 5$ piksela, na osnovu vidljivosti gradijenta $i$ jačine lokalne koherencije:

$$
\begin{gathered}
w q(n)=\frac{1}{P} \sum_{p=1}^{P} \frac{G_{v i s}(p)}{1+e^{-30\left(G(p)-T_{g}\right)}}\left(L C>T_{L C}\right), \\
n=1, \ldots, N \#
\end{gathered}
$$

$T_{L C}$ je parametar optimizacije. $N$ je broj prozora u slici, a $P$ broj piksela u prozoru.

Svakom prozoru dodeljuje se indikacija vidljivosti. Kriterijum koji treba da bude zadovoljen da bi prozor bio vidljiv je da prosečni vidljivi gradijent bude veći od praga vidljivosti $T_{v i s}$, koji je jedan od parametara optimizacije. Zadržavaju se samo vrednosti $w q$ koje odgovaraju strukturama koje se nalaze u vidljivim prozorima.

Konačna procena kontrasta $C_{q}$ dobija se usrednjavanjem $w q$ po svim prozorima, nakon čega se vrednost skalira faktorom globalne vidljivosti slike, odnosno procentom vidljivih prozora.

$$
C_{q}=\frac{1}{N^{2}} \sum_{n=1}^{N} w q(n) w v(n)
$$

\subsection{Oštrina}

$\mathrm{Za}$ objektivnu procenu optine koriščene su tri mere zasnovane na analizi gradijenta.

Prvi korak je filtriranje slike niskopropusnim Gausovim filtrom. Za ulaznu sliku, kao i za sliku niže rezolucije $\left(i m_{L R}\right)$ se traže gradijenti promena po horizontalnom i vertikalnom pravcu, kao i snaga gradijenta na nižoj rezoluciji $G_{L R}$.

Parametrom optimizacije određuje se procenat lokacija koje će biti korišćene za evaluaciju, te se na osnovu toga definiše donja granica intenziteta gradijenta koja određuje koji delovi snimka će uticati na procenu. Na izdvojenim značajnim lokacijama se na nivou piksela računa odnos gradijenata na višoj i nižoj rezoluciji. Na ovaj način se prati promena oštrine sa opadanjem rezolucije. Velika oštrina slike će se očuvati i na manjoj rezoluciji, dok će se manje oštre strukture lakše eliminisati ublažavanjem.

Krajnji rezultat mere srazmeran je medijanu oštrine u tačkama procene i ograničen je na opseg $[0,1]$, pri čemu veće vrednosti ozačavaju bolji kvalitet:

$$
S h_{q_{1}}=\sqrt{\frac{\max \left(\operatorname{median}\left(S h_{1}(n, m)\right)-1,0\right)}{1.6}}
$$

Mera $S h_{q_{2}}$ je mala modifikacija opisanog algoritma. Uveden je dodatni parametar optimizacije $T_{i}$, koji definiše gornji procenat opsega intenziteta slike koji se analizira, kako bi se procena oštrine ograničila samo na signal koji odgovara značajnim strukturama, a pozadina izbacila iz analize.

Treća modifikacija je mera $S h_{q_{3}}$, u kojoj se uvodi i uticaj kontrasta. Ideja je da se procena oštrine ograniči samo na regije na kojima je kontrast dovoljno jak.

\section{PODACI}

Za analizu objektivnih mera i evaluaciju njihovih rezultata korišćeno je 300 dijagnostičkih radiografskih snimaka. U toku redovne kliničke prakse za akviziciju snimaka korišćen je Trixell Pixium 4343 detektor koji sadrži 2880 x 2880 kvadratnih piksela širine $0.148 \mathrm{~mm}$. Prikupljeno je 100 snimaka koji su potom obrađeni korišćenjem dva algoritma, MUSICA $2^{\circledR}[8]$ i dva različita XPRP pristupa [9], sa ciljem da se što više eliminiše šum i povećaju kontrast i oštrina struktura.

Ovako dobijeni skup od 300 snimaka je podeljen u 10 kategorija sa po 30 snimaka, na osnovu anatomskih regija koje su snimane. Primer nekoliko snimaka iz skupa dat je na Slici 2.

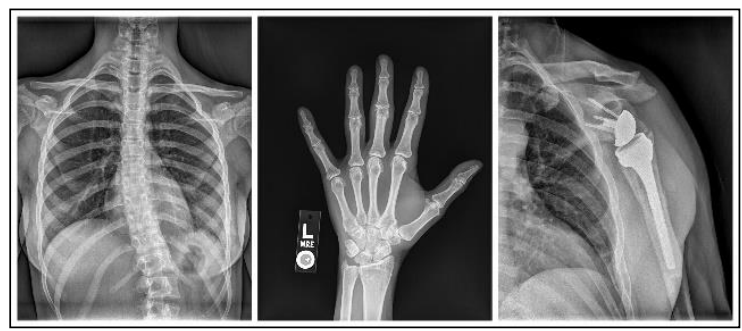

Slika 2. Primer snimaka iz korišćenog skupa

Sprovedeno je ispitivanje u okviru koga su dva dijagnostička radiologa ocenila svaki snimak iz skupa na osnovu tri kriterijuma kvaliteta, oslanjajući se na svoj subjektivni utisak. Ocenama od 1 do 5 ocenjeno je prisustvo šuma, kontrast i oštrina.

\section{REZULTATI}

Uspešnost objektivnih mera ocenjuje se na osnovu korelacije njihovih rezultata za subjektivnim ocenama. Korišćen je Spirmanov koeficijent korelacije rangova $(S R O C C)$ [10]:

$$
S R O C C=1-\frac{6 \sum d^{2}}{n\left(n^{2}-1\right)}
$$

$n$ je broj elemenata u vektoru rezultata procene, a $d$ rastojanje između odgovarajućih elemenata vektora subjektivne i objektivne procene.

Pogodno je koristiti ovu korelaciju jer rezultat ne zavisi od konkretne vrednosti ocena već se poredi njihov rang. Vrednost koeficijenta korelacije može biti u opsegu [-1, 1], pri čemu veće vrednosti označavaju veću korelaciju.

U Tabeli 1 date su vrednosti koeficijenata korelacije za sve kategorije i različite mere. 
Tabela 1. SROCC za različite mere za sve kategorije snimaka

\begin{tabular}{|l|c|c|c|c|}
\hline & $L C_{1}$ & $L C_{2}$ & $C_{q}$ & $S h_{q_{1}}$ \\
\hline Abdomen AP & 0.35 & 0.80 & 0.65 & 0.80 \\
\hline Pluća LAT & 0.50 & 0.65 & 0.55 & 0.85 \\
\hline Pluća PA & 0.65 & 0.80 & 0.15 & 0.90 \\
\hline $\begin{array}{l}\text { Cervikalna } \\
\text { kičma LAT }\end{array}$ & 1 & 1 & 0.40 & 0.35 \\
\hline Šaka AP & 1 & 1 & 0.80 & 0.30 \\
\hline Koleno AP & 1 & 1 & 0.50 & 0.70 \\
\hline $\begin{array}{l}\text { Lumbalna } \\
\text { kičma LAT }\end{array}$ & 1 & 1 & 0.25 & 0.70 \\
\hline Karlica AP & 0.65 & 0.75 & 0.90 & 0.90 \\
\hline Rame AP & 0.85 & 0.85 & 0.25 & 0.50 \\
\hline $\begin{array}{l}\text { Torakalna } \\
\text { kičma AP }\end{array}$ & 1 & 1 & 0.85 & 0.90 \\
\hline
\end{tabular}

$\mathrm{Za}$ većinu anatomskih kategorija mera $L C_{1}$ ostvarila je dosta visoku korelaciju, a posebno visok nivo poklapanja sa subjektivnim utiskom postignut je na slikama kostiju. Ostvareno je idealno poklapanje na svim snimcima kičme, kao i na snimcima šake i kolena.

Mera $L C_{2}$ definisana je sa idejom da se poboljša procena šuma na snimcima mekih tkiva i za sve kategorije mekih tkiva postignuto je poboljšanje korelacije.

Poklapanje sa subjektivnim utiskom nije toliko izraženo kao za snimke kostiju, međutim ostvareno je značajno poboljšanje za snimke pluća, i naročito abdomena. Blago poboljšanje ostvareno je i na snimcima karlice, na kojima iako dominira koštano tkivo ipak postoji nezanemarljiva količina mekih struktura.

Rezultati mere za kontrast variraju nezavisno od vrste tkiva koje je prikazano na snimku. Visoka korelacija je ostvarena za snimke šake, karlice i torakalne kičme.

Visoka korelacija sa subjektivnim ocenama za meru $S h_{q_{1}}$ ostvarena je na snimcima pluća u PA projekciji, karlice i torakalne kičme. Nešto malo manje poklapanje dobijeno je na snimcima abdomena i pluća u LAT projekciji. Može se primetiti da mera generalno bolje radi na snimcima mekih tkiva jer se analiza radi na nižoj rezoluciji, gde se očuvavaju manje izražene strukture koje odgovaraju mekom tkivu. Sa druge strane, gube se detalji koji postoje na kostima, pa se mera loše pokazala na tim kategorijama snimaka.

Modifikacijama koje unose mere $S h_{q_{2}}$ i $S h_{q_{3}}$ nisu poboljšani rezultati mere $S h_{q_{1}}$.

\section{ZAKLJUČAK}

U ovom radu predstavljene su mere količine šuma, kontrasta $\mathrm{i}$ oštrine, dizajnirane tako da oponašaju mehanizme subjektivne percepcije kvaliteta, sa ciljem da daju procene koje se poklapaju sa subjektivnim utiscima dijagnostičkog kvaliteta radiologa.

Veoma dobri rezultati ostvareni su po pitanju procene šuma. Mera $L C_{1}$ odlično radi na snimcima kostiju, pa je za sve kategorija snimaka kičme, kao i snimke ruke i kolena, ostvarena idealna korelacija. Mera $L C_{2}$ je dizajnirana da bi se poboljšali rezultati procene na snimcima mekih tkiva, $\mathrm{i}$ ostvareno je značajno povećanje poklapanja za snimke abdomena i pluća.

Procena kontrasta nije bila preterano uspešna, ali je ostvarena solidna korelacija na snimcima šake, karlice i torakalne kičme.

Isprobana su tri pristupa za izdvajanje struktura značajnih za procenu oštrine i najbolje se pokazalo korišćenje kriterijuma za izraženost struktura. Rezultati su ujednačeno visoki za snimke mekih tkiva, a visoka korelacija ostvarena je i za snimke karlice i torakalne kičme.

U budućem radu trebalo bi poboljšati meru za oštrinu, naročito za ostale kategorije snimaka kostiju, a takođe bi se mogli ispitati alternativni pristupi za procenu kontrasta. Krajnji cilj je kombinacija procena svih faktora kvaliteta u jednu opštu meru dijagnostičkog kvaliteta radiografskog snimka.

\section{LITERATURA}

[1] V. Ostojić, Đ. Starčević, V. Petrović, "Recursive anisotropic diffusion denoising," Electronics Letters, vol. 52, no. 17, pp. 1449-1451, 2016.

[2] P. Irrera, I. Bloch, M. Delplanque, “A flexible based approach for combined denoising and contrast enhancement of digital X-ray images", Medical Image Analysis, Elsevier, vol. 28, pp. 33-45, 2016.

[3] P. Sprawls, " Physical principles of medical imaging", 2nd ed., Gaithersburg, Aspen Publishers, 1993.

[4] W. Birkfellner, “Applied Medical Image Processing”, 2nd ed., Boca Raton, FL, Taylor \& Francis, 2014.

[5] W. Huda, R. B, Abrahams, "X-Ray-Based Medical Imaging and Resolution", American Journal of Roentgenology, vol. 204, no. 4, pp. 393-397, 2015.

[6] T. N. Pappas, R. J. Safranek, "Perceptual criteria for image quality evaluation", Handbook of Image and Video Processing, pp. 669-684, Academic Press, 2000.

[7] M. K. Mandal, "The Human Visual System and Perception", Multimedia Signals and Systems, The Springer International Series in Engineering and Computer Science, vol. 716, pp. 33-56, Boston, MA, 2003.

[8] R. Schaetzing, "Agfa's musica2 taking image processing to the next level", AGFA Health Care, Tech. Rep., 2007.

[9] V. Ostojić, "Integrisana multiveličinska obrada radiografskih snimaka," Doktorska disertacija, Fakultet tehničkih nauka, Univerzitet u Novom Sadu, Novi Sad, Srbija, 2018.

[10] Y. Dodge, "The Concise Encyclopedia of Statistics", New York, Springer, 2008.

\section{Kratka biografija:}

Aleksandra Zec rođena je Novom Sadu 1996. god. Osnovne studije Biomedicinskog inženjerstva na Fakultetu tehničkih nauka završila je 2019. god. Master studije na Fakultetu tehničkih nauka iz oblasti Energetika, elektornika i telekomunikacije, usmerenje Obrada signala završila je 2020. godine. Kontakt: aleksandra.zec@uns.ac.rs 